\title{
A novel UWB reconfigurable filtering antenna design with triple band-notched characteristics by using u-shaped coppers
}

\author{
I.D. Saiful Bahri, Z. Zakaria, N. A. Shairi, N. Edward
}

Centre of Telecommunication Research and Innovation (CeTRI), Faculty of Electronic \& Computer Engineering, University Teknikal Malaysia Melaka (UTeM), Malaysia

\begin{tabular}{l} 
Article Info \\
\hline Article history: \\
Received Sep 29, 2018 \\
Revised Nov 27, 2018 \\
Accepted Dec 12, 2018 \\
\hline Keywords: \\
Monopole antenna \\
Reconfigurable filtering \\
antenna \\
Triple-band notched \\
U-shaped coppers \\
\hline
\end{tabular}

\begin{abstract}
This paper proposed an UWB antenna with triple reconfigurable notch filters. By presenting there U-shaped coppers in the design, the potential triple interference in UWB applications can be rejected. Six PIN diodes are putted on the coppers to represent the OFF and ON tunable status in order to add reconfigurable characteristics to the UWB antenna. By using this $\mathrm{ON}$ and OFF tunable method, the current distribution of the proposed design changes and enables the antenna to have eight operation modes. The results prove that the proposed design can operate over the entire UWB frequency range (3.1 GHz to $10.6 \mathrm{GHz}$ ) and can filter out the target signals from the WLAN upper band (5.725 to $5.825 \mathrm{GHz})$, WLAN lower band $(5.15$ to $5.35 \mathrm{GHz})$ and $\mathrm{X}$ band frequency system ( 7.9 to $8.4 \mathrm{GHz})$ in one of the tunable configurations.

Copyright (c) 2019 Institute of Advanced Engineering and Science. All rights reserved.
\end{abstract}

\section{Corresponding Author:}

Zahriladha bin Zakaria,

Centre of Telecommunication Research and Innovation (CeTRI),

Faculty of Electronic \& Computer Engineering,

Universiti Teknikal Malaysia Melaka (UTeM),

Jalan Hang Tuah Jaya, 76100 Durian Tunggal, Melaka, Malaysia.

Email: zahriladha@utem.edu.my

\section{INTRODUCTION}

Ultra-wideband (UWB) technology is a radio technology that has low power consumption, wide impedance bandwidth and high data rate for short-range. UWB has been integrated with many applications in other fields, for example in radar detection sensor [1], medical engineering [2], and wireless communications. Due to robustness against fading, multiple accurate positioning and low cost transceivers [3], the interest in UWB application has gained the tremendous attention from the researcher.

There are challenges in UWB technology. One of these challenges is UWB technology as reported in [4] is facing interference problem with other narrowband systems such as WiMAX (3.3 to $3.7 \mathrm{GHz}$ ), HiperLAN2 (5.47 to $5.725 \mathrm{GHz})$, WLAN (5.15 to $5.35 \mathrm{GHz}, 5.725$ to $5.825 \mathrm{GHz}$ ) and X band satellite frequency system $(7.9$ to $8.4 \mathrm{GHz})$.

In [5], integrating a band stop filter with the UWB antenna in separate element successfully reduces the possible interference and remove the interfering signals. In contrast, it increases complexity, loss, weight and cost of the design. Consequently, it is desirable to integrate the UWB antenna and filter into a single element to increase the performance of filtering antenna design.

Most researchers nowadays tend to integrate band rejected structure in the UWB antenna design to provide band notch characteristics and reject unwanted frequency [6], [7]. Different techniques have been introduced to obtain the band notch elements such as introducing parasitic strips near the ground plane or the radiation patch [8][9] and by cutting different shaped slots in the ground plane or the radiation patch. For example, by cutting C-shaped [10], U-shaped [11], H-shaped [12], pi-shaped [13], and L-shaped slots [14]. However, the band rejection structures on the radiation patch and ground plane effect the 
performance of radiation. Moreover, many techniques are studying and only fixed notched band is produced [15]-[18].

Recently, the research interest in reconfigurable filtering-antenna have increased dramatically [19], [20]. With the development of modern technology, the numbers of narrow interference communication and license bands are expanding in the UWB range band frequency. Thus, to cope with the this situation, reconfigurable become another notable aim of UWB antenna design which can be used as a normal UWB antenna and as single, dual and triple band notched [21].

This paper proposed an UWB triple reconfigurable filtering antenna. First, the proposed antenna is modified to formed the antenna with better return loss performance and able to cover all the UWB bandwidth. Then, three U-shaped coppers are inserted on the antenna to generate the band notched elements. Lastly, six PIN diode are located on the coppers which act as a reconfigurable system in this design. Eight modes of operation are produced by controlling the ON/OFF condition of the PIN diode states.

If the proposed antenna be compare with [22], it should note that the numbers of mode of design has been increase from four to eight modes. In other references [23], although they can achieve triple notched filter there are disadvantages, including only fixed notched is introduced and the size of antenna in [23] is larger than in proposed design.

Furthermore, in [24], [25], they generated single and dual reconfigurable, respectively against triple reconfigurable notched in presented design. In addition, in [26], although they successfully produced triple reconfigurable notched filter there are negative issue including produce excessive band rejection in WLAN frequency which leads to reject wanted signal. Another advantage is the proposed design is simple since only U-shaped copper are utilized compared than in [27].

\section{ANTENNA DESIGN}

Figure 1 shows the configuration of the proposed UWB antenna which is designed using a circular modified monopole antenna. The proposed antenna is mounted on Roger Duroid 5880 which has a thickness is $0.787 \mathrm{~mm}$ and relative permittivity is 2.2 . The antenna design is fed by $50 \mathrm{ohm}$ of impedance transmission line and partially ground plane printed on the lower side of the antenna. From [28]-[30], by modifying the patch and feedline of the ordinary monopole antenna, the performance gain is improved while improving the return loss characteristic. Figure 1 illustrates the structure of the proposed UWB antenna with feedline and patch modification with the optimum value in millimeter.

Figure 2 shows the simulated result of the reflection coefficient for the proposed UWB antenna design. From the result, it can be concluded that the antenna cover from $3.1 \mathrm{GHz}$ to $11.21 \mathrm{GHz}$, which cover all the UWB antenna bandwidth. The propose design also provide better skirt selectivity frequency than reported in [31] which is average above $-20 \mathrm{~dB}$.

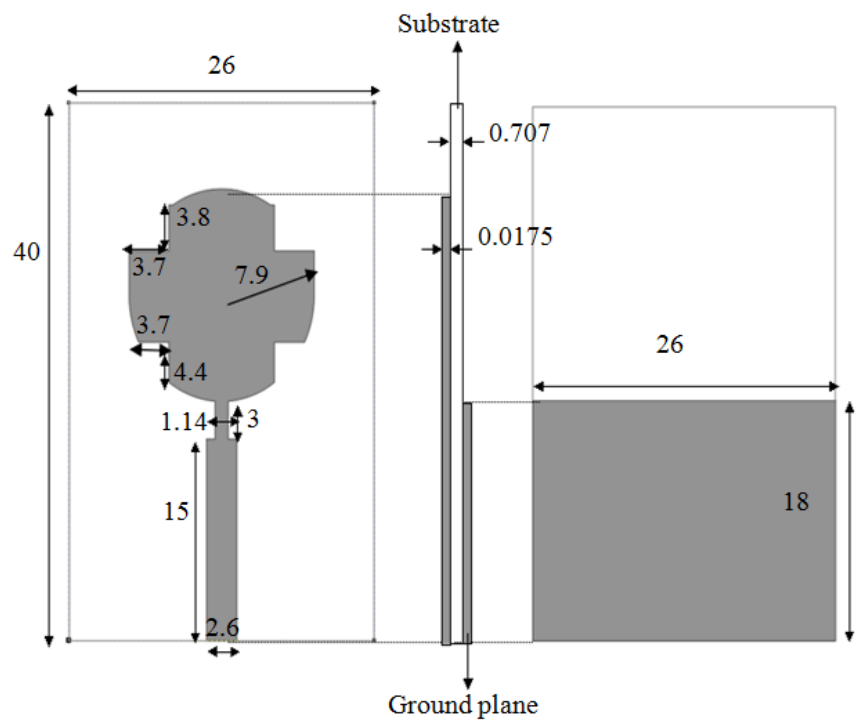

Figure 1. Simulated structure of antenna with feedline and patch modification of UWB antenna

Indonesian J Elec Eng \& Comp Sci, Vol. 14, No. 1, April 2019 : 267 - 275 


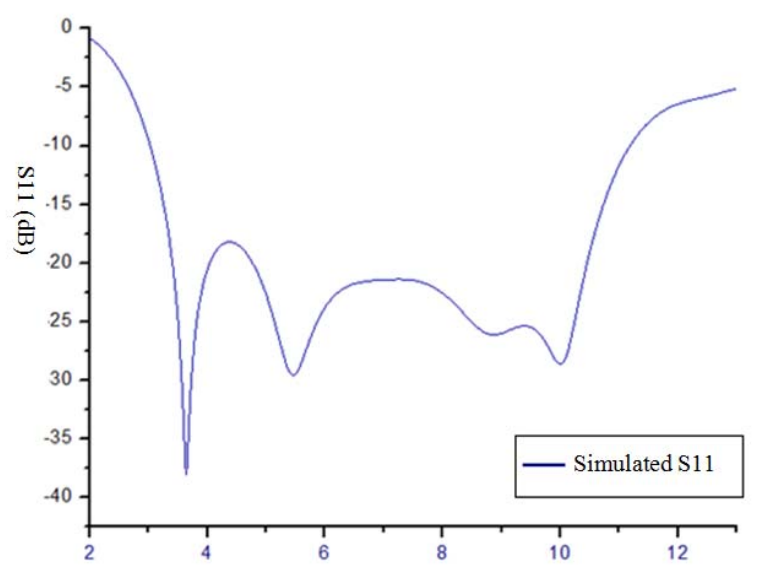

Figure 2. S11 simulated of proposed UWB antenna

\section{TRIPLE NOTCHED BAND DESIGN}

In this section, we introduce three $U$ shaped notch filter to act as a triple band rejection to reject potential interference from WLAN $(5.15$ to $5.35 \mathrm{GHz}, 5.725$ to $5.825 \mathrm{GHz})$ and uplink of X band satellite communication system (7.9 to $8.4 \mathrm{GHz})$ in UWB frequency. In [32][33], U-shaped coppers notch filter are designed by using the (1) and (2):

$$
\begin{aligned}
& L=\frac{\lambda_{g}}{2} \\
& \lambda_{g}=\frac{c}{f_{\text {notch }} \sqrt{\varepsilon_{\text {eff }}}}
\end{aligned}
$$

where: $\lambda_{g}=$ Guided wavelength of the notch frequency

$\mathrm{L}=$ Approximated length of the U-shaped copper

$\varepsilon_{\text {eff }}=$ Antenna effectiveness

The band rejection elements on the ground plane and radiation patch influence the UWB radiation characteristics. Therefore, in this research U-shaped coppers are avoiding that area. The design then are optimized by using a parametric study to increase the performance of filtering antenna.

The dimension and design of the U-shaped coppers are shown in Table 1 and Figure 3, respectively. From the study, each band notched filter can be tuned independently and can perform the operation separately. Figure 4 shows the fabricated design of the proposed design in Figure 3.

Table 1. Dimension of Proposed U-shaped Coppers

\begin{tabular}{cccc}
\hline Parameter & Values $(\mathrm{mm})$ & Parameter & Values $(\mathrm{mm})$ \\
\hline $\mathrm{La}$ & 5.95 & $\mathrm{Wa}$ & 12 \\
$\mathrm{Lb}$ & 4.7 & $\mathrm{~Wb}$ & 11.5 \\
$\mathrm{Lc}$ & 8.0 & $\mathrm{Wc}$ & 10.38 \\
\hline
\end{tabular}




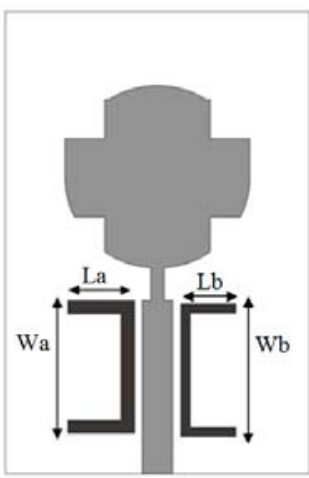

(a)

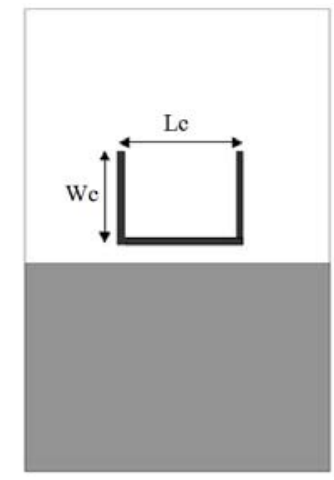

(b)

Figure 3. The simulated design of U-shaped coppers in the proposed design. (a) Top view (b) Bottom view

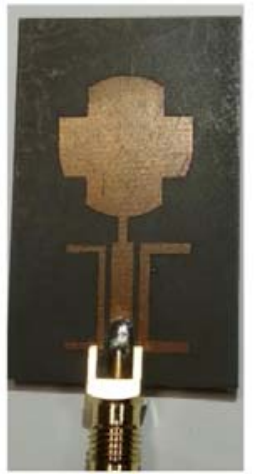

(a)

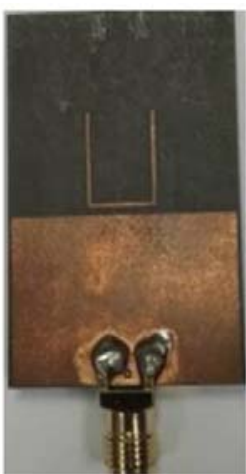

(b)
Figure 4. The fabricated design of U-shaped coppers in the proposed design. (a) Top view (b) Bottom view

Figure 5 shows the reflection coefficient for antenna design in Figure 3 and Figure 4 for simulation and measurement process. Simulated result shows that the S11 of the proposed design is less than 2 from $3 \mathrm{GHz}$ to $11.2 \mathrm{GHz}$, except for the unwanted band notched frequency from $5.15 \mathrm{GHz}$ to $5.35 \mathrm{GHz}, 5.725 \mathrm{GHz}$ to $5.825 \mathrm{GHz}$ and 7.9 to $8.4 \mathrm{GHz}$. However, the frequency shift between the simulated and measured results can be Noticed. From [24][26][34] and after going through further study, it may happen due to fabrication tolerance and inaccuracy during cutting the edge of substrate in the fabrication process. Table 2 explains the comparison between simulated and measured results of the proposed triple band notched UWB antenna in Figure 3 and Figure 4.

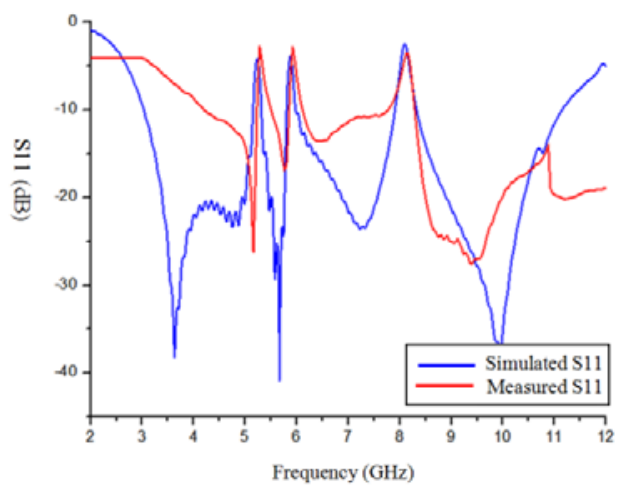

Figure 5. The S11 results for antenna design in Figure 3 simulation and measurement design.

Table 2. Comparison of Triple Notched Band Frequency in Simulation and Measurement Design

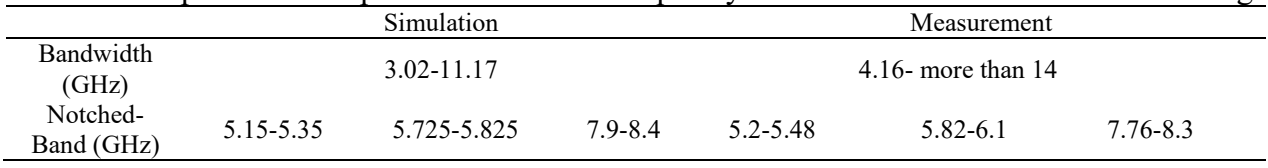

The surface current distribution is studied to understand the principle of the proposed UWB monopole antenna with triple band-notched and investigate the influence radiating coppers toward the UWB antenna. From Figure 6, the current distribution at the notch $5.2 \mathrm{GHz}, 5.8 \mathrm{GHz}$ and $8 \mathrm{GHz}$ is focused mainly on the left side of feedline, right side of the antenna and above the ground, respectively. It is indicated that all three coppers are capable of rejecting the band notched. 


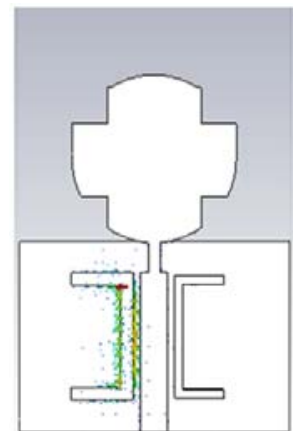

(a)

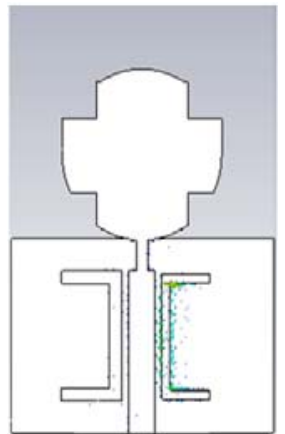

(b)

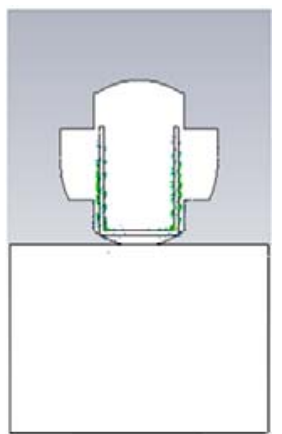

(c)

Figure 6. Simulated surface current distribution of proposed triple band-notched UWB antenna at various frequencies of (a) $5.2 \mathrm{GHz}$, (b) $5.8 \mathrm{GHz}$ and (c) $8 \mathrm{GHz}$

\section{RECONFIGURABLE NOTCHED BANDS DESIGN}

The PIN diode are putted on the coppers to behave as variable resistor with ON and OFF operating states [35], [36]. Frequency reconfigurable can achieve by control and changing the equivalent RLC circuit of the PIN diode. Table 3 explains the lumped RLC network condition, according to the RLC equivalent circuit in both state (ON/OFF) [37].

The position of the diode is investigated. As reported in [38], the used of the PIN diodes result a small frequency shift to lower frequency. However, this frequency shift can be overcome by adjusting the placement of diode or adding the number of diodes on the antenna. Here, after going further on the parametric study, the position of the diode is optimized and the number of diodes is added to six diodes. Figure 7 shows the optimum position of diodes in this design.
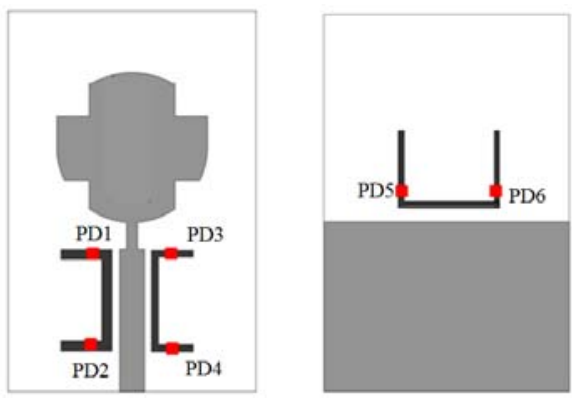

Figure 7. Position of the PIN Diodes

Table 3. Details of PIN Diodes Lumped Elements

\begin{tabular}{lll}
\hline RLC circuit & \multicolumn{1}{c}{ Details } & State \\
\hline & $\begin{array}{l}\text { 1. Forward biased. } \\
\text { 2. Has a low resistance which allow the current } \\
\text { to pass. }\end{array}$ & On \\
3. Acts as short circuit. & & \\
4. Existence of notch.
\end{tabular}


Table 4 explains the operating modes of the purposed reconfigurable triple band notch conditions. The mode of the targeted notched band of WLAN upper band (5.725-5.825 GHz ), WLAN lower band (5.15-5.35 GHz) and $\mathrm{X}$ satellite band $(7.9-8.4 \mathrm{GHz})$ are controlled by the On and OFF states of PIN diodes. These operational modes enable the antenna to have eight modes of operation by control the changes in current distribution of the patch.

Table 4. Operating Modes of the Purposed Reconfigurable Triples Band Notched Conditions

\begin{tabular}{ccccc}
\hline Mode & PD1 & PD3 & PD5 & Notched Band \\
& PD2 & PD4 & PD6 & \\
\hline 1 & OFF & OFF & OFF & UWB antenna \\
2 & OFF & OFF & ON & $7.9 \mathrm{GHz}$ \\
3 & OFF & ON & OFF & $5.725 \mathrm{GHz}$ \\
4 & OFF & ON & ON & $5.725 \mathrm{GHz}$ and $7.9 \mathrm{GHz}$ \\
5 & ON & OFF & OFF & $5.15 \mathrm{GHz}$ \\
6 & ON & OFF & ON & $5.15 \mathrm{GHz}$ and $7.9 \mathrm{GHz}$ \\
7 & ON & ON & OFF & $5.15 \mathrm{GHz}$ and $5.725 \mathrm{GHz}$ \\
8 & ON & ON & ON & Triple band-notched \\
\hline
\end{tabular}

Figure 8 shows the simulated reflection coefficient of eight combination modes in Table 4 . In OFF states, which is in mode 1, the proposed design operated in 3.12 to $11.2 \mathrm{GHz}$ frequency bands which covers the full UWB applications and act as the design in Figure 1.

On the other hand, it other all modes (from mode 2 to mode 8), the reflection coefficient of the proposed design during the $\mathrm{ON}$ state is less than $-10 \mathrm{~dB}$ in the corresponding rejected frequency. The activation of diode produced the bandstop filtering element. No operation resonance is generated and all the signal is reflected back. As a result, it generates the impedance mismatching to achieve the targeted rejection band.

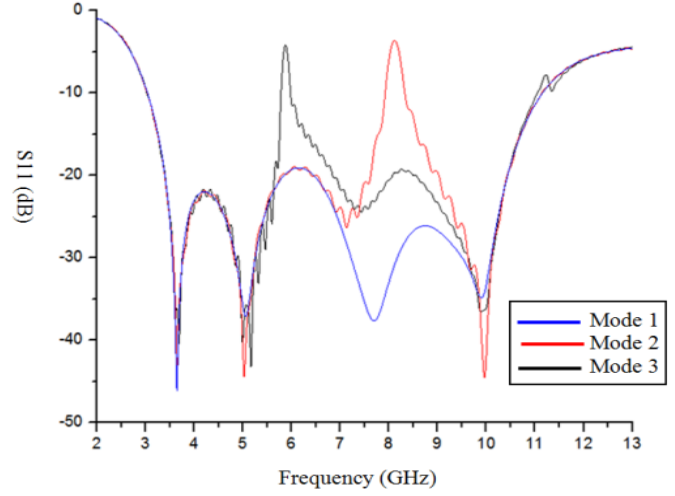

(a)

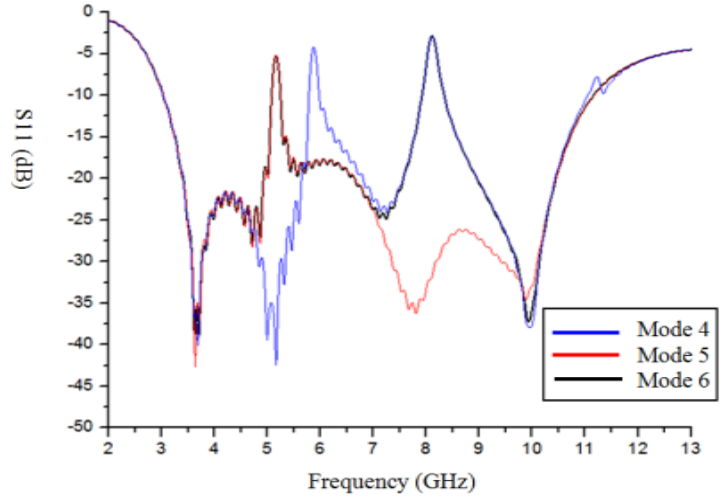

(b)

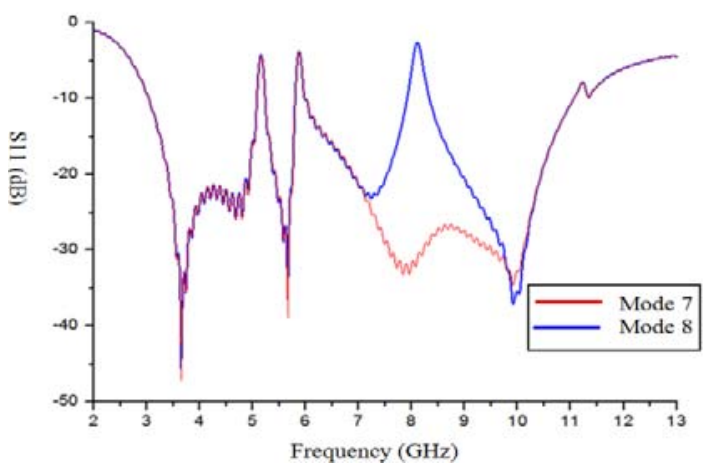

(c)

Figure 8. Simulated reflection coefficient of eight operating modes in Table 4. (a) Mode 1, Mode 2 and Mode 3 (b) Mode 4, Mode 5 and Mode 6 (c) Mode 7 and Mode 8 


\section{CONCLUSION}

This paper presented circular modified monopole antenna with triple bands reconfigurable for UWB application from WLAN $(5.15 \mathrm{GHz}$ and $5.75 \mathrm{GHz})$ and X-band satellite $(7.25 \mathrm{GHz})$. Three U-shaped coppers is inserted in the UWB antenna design to generate three bandstop filters. Tunable technique is introduced to control the operational mode in this design and can be used to reject reject single, dual or triple notch band in UWB range of frequency. Further investigation of reconfigurable notch filter will be carried out in future works in order to investigate the overall performance of this design through the experimental works. Furthermore, biasing circuit need to be considered in this design to increase the performance reconfigurable UWB antenna.

\section{ACKNOWLEDGEMENTS}

The author would like to thank Mybrain15 program for sponsoring this study and to Center for Research and Innovation Management (CRIM), Centre of Excellent UTeM, UTeM's research grant JURNAL/2018/FKEKK/Q00001 and Universiti Teknikal Malaysia Melaka (UTeM) for their encouragement and help in supporting this work.

\section{REFERENCES}

[1] M. Jusoh, M. F. Jamlos, M.R.K., M. F. Malek, M. A. Romli, Z. A. Ahmad, M.H.M. and Zulkifli, and M.S., “A reconfigurable ultrawideband (UWB) compact tree-design antenna system", Progress In Electromagnetics Research, 30(June), pp.131-145, 2012.

[2] Osman, M. a R. et al., "Embroidered Fully Textile Wearable Antenna for Medical Monitoring Applications", Progress in Electromagnetics Research-Pier, 117(May), pp.321-337. 2011.

[3] Liao, Z. et al., "An omni-directional and band-notched ultra wideband antenna on double substrates crossing", Progress In Electromagnetics Research C, 22(May), pp.231-240, 2011.

[4] Science, R., "Compact Integrated Bluetooth UWB Antenna with Quadruple Bandnotched Characteristics", International Journal of Electrical and Computer Engineering (IJECE), 5(6), pp.1433-1440, 2015.

[5] Chu, Q.X. and Yang, Y.Y., "A compact ultrawideband antenna with 3.4/5.5 GHz dual band-notched characteristics", IEEE Transactions on Antennas and Propagation, 56(12), pp.3637-3644, 2008.

[6] Yadav, S., Gautam, A.K. and Kanaujia, B.K., "Design of dual band-notched lamp-shaped antenna with UWB characteristics", International Journal of Microwave and Wireless Technologies, pp.1-8, 2015.

[7] Yadav, S., Gautam, A.K. and Kanaujia, B.K., "Design of dual band-notched lamp-shaped antenna with UWB characteristics", International Journal of Microwave and Wireless Technologies, pp.1-8, 2015.

[8] C.-M. Li and L.-H.Ye, "Improved dual band-notched UWB Slot Antenna with Controllable Notched Bandwidths", Progress In Electromagnetics Research, vol. 115, pp. 477-493, 2011.

[9] A. Abbosh and M. Bialkowski, "Design of UWB planar band-notched antenna using parasitic elements", Antennas and Propagation, IEEE Transactions on, vol. 57, pp. 796-799, 2009.

[10] M. Abdollahvand, G. Dadashzadeh, and D. Mostafa, "Compact Dual Band-notched Printed Monopole Antenna for UWB Application", Antennas and Wireless Propagation Letters, IEEE, vol. 9, pp. 1148-1151, 2010.

[11] J. R. Panda and R. S. Kshetrimayum, "A Compact CPW-Fed Monopole Antenna With An U-Shaped Slot For 5 GHz/6 GHz Band-Notched Ultra wideband Applications", India Annual IEEE Conference (INDICON), 2009.

[12] M. N. Shakib, M. T. Islam, and N. Misran, "Stacked Patch Antenna with Folded Patch Feed for Ultra-wideband Application", IET Microwaves, Antennas \& Propagation, vol. 4, pp. 1456-1461, 2010.

[13] M.-C. Tang, S. Xiao, T. Deng, D. Wang, J. Guan, B. Wang, et al., "Compact UWB Antenna with Multiple BandNotches for WiMAX and WLAN", Antennas and Propagation, IEEE Transactions, vol. 59, pp. 1372-1376, 2011.

[14] Jian Wei Wang, Jing Yuan Pan, Xiao Na Ma and Yun Qing Sun, "A Band-Notched UWB Antenna with L-Shaped coppers and Open-Loop Resonator", IEEE International Conference Applied Superconductivity and Electromagnetic Devices (ASEMD), pp. 312 - 315, 2013.

[15] M. Ojaroudi, N. Ojaroudi and N. Ghadimi, "Dual Band-Notched Small Monopole Antenna with Novel Coupled Inverted U-ring Strip and Novel Fork-Shaped Slit for UWB Applications", IEEE Antennas Wireless Propagation Letters, vol. 12, pp. 182-185, 2013.

[16] Y. Li, Wi. Li and R. Milttra, "Miniaturized CPW-fed UWB Antenna with Dual Frequency Rejection Bands using Stepped Impedance Stub and Arc-shaped Parasitic Element", Microwave and Optical Technology Letter, vol.. 56, no. 4, pp. 783-787, 2014.

[17] X. Luo, J. G. Ma, K. Ma, and K. S. Yeo, "Compact UWB Bandpass Filter with Ultra Narrow Notched Band", IEEE on Microwave and Wireless Components Letters, vol. 20, no. 3 pp. 145-147, 2010.

[18] Q. Li, Z. J. Li, C. H. Liang, \& B. Wu, "UWB Bandpass Filter with Notched Band Using DSRR", Electronics Letters, vol. 46, no. 10, pp. 692-693, 2010.

[19] L. Yao, H. Wei, and W. Ke, "Tunable Microstrip Ring Bandpass Filter", Microwave Conference Proceedings (CJMW), China-Japan Joint, pp. 1-3, 2011.

[20] Y. Li and Q. Ye, "A Reconfigurable Triple Notch Band Antenna Integrated with Defected Microstrip Structure Band-Stop Filter for Ultra-Wideband Cognitive Radio Applications", International Journal of Antennas and Propagation, pp. 1-13, 2013. 
[21] B. Hammache, A. Messai, I. Messaoudene, M. A. Meriche, M. Belazzoug and F. Chetouah, "Reconfigurable Triple Notched-Band Ultra Wideband Antenna", 12th International Conference on Innovations in Information Technology (IIT), pp. 1-5, 2016.

[22] Wael A.E Ali and Rana M. A. Moniem, "Frequency Reconfigurable Triple Band-Notched Ultra-Wideband Antenna with Compact Size", Progress In Electromagnetics Research, vol. 73, pp. 37-46, 2017.

[23] Deqiang Yang, Sihao Liu, Mengfei Chen and Yubo Wen, "A Compact Vivaldi Antenna with Triple Band-Notched Characteristics", IEEE 6th International Symposium on Microwave, Antenna, Propagation, and EMC Technologies (MAPE), Shanghai, pp. 216-219, 2015.

[24] A. A. Ibrahim and R. M. Shubair, "Reconfigurable band-notched UWB Antenna for Cognitive Radio Applications", 2016 16th Mediterranean Microwave Symposium (MMS), pp. 1-4, 2016.

[25] S. Y. Chen and Q. X. Chu, "A Reconfigurable Dual Notched-Band UWB Antenna", IEEE 4th Asia-Pacific Conference on Antennas and Propagation (APCAP), pp. 103-104, 2015.

[26] Chao-Ming Luo, Jing-Song Hong, Muhammad Amin and Lei Zhong, "Compact UWB Antenna with Triple Notched Bands Reconfigurable", 2016 IEEE International Conference on Microwave and Millimeter Wave Technology (ICMMT), Beijing, pp. 746-748, 2016.

[27] S. Kumar, R. D. Gupta and M. S. Parihar, "Multiple Band Notched Filter Using C-Shaped and E-Shaped Resonator for UWB Applications", IEEE Microwave and Wireless Components Letters, vol. 26, no. 5, pp. 340-342, May 2016.

[28] C. A. Balanis, “Antenna Theory, Analysis and Design”, $3^{\text {rd }}$ edition. John Wiley \& Sons, Inc, 2015.

[29] Patre, S. R and Singh, S. P, "CPW-fed Flower-Shaped Patch Antenna for Broadband Applications", Microwave and Optical Technology Letters, pp. 2781-2784, 2012.

[30] Pourahmadazar, J. Ghobadi, C. And Nourinia, J, "Novel Modified Pyhthagorean Tree Fractal Monopole Antennas for UWB Applications", IEEE Antennas and Wireless Propagation Letters, vol. 10, pp. 484-487, 2011.

[31] M. C. Tang, H. Wang, T. Deng and R. W. Ziolkowski, "Compact Planar Ultrawideband Antennas With Continuously Tunable, Independent Band-Notched Filters", IEEE Transactions on Antennas and Propagation, vol. 64, no. 8, pp. 3292-3301, Aug. 2016.

[32] Raju. P. A and Behera, S. K, "Frequency Reconfigurable Microstrip Antenna for Cognitive Radio Applications", IEEE International Conference, 2015.

[33] R. A. Abdulhasan, R. Alias, A. A. Awaleh, A. O. Mumim, "Design of Circular Patch Microstrip Ultra Wideband Antenna with Two Notch Filters", IEEE international Conference on Computer, Communication and Control Technology (14ICT), pp. 464-467, 2015.

[34] Wu, L., Xia, Y. \& Cao, X, "Design of Compact Quad-Band Notched UWB-MIMO Antenna", Wireless Personal Communication, 2017.

[35] Rayno. J. T and Sharma, S. K, "Frequency Reconfigurable Spirograph Planar Monopole Antenna (SPMA)", Proceedings of ISAP, pp. 1305-1308, 2012.

[36] A. Musavand, Y. Zehforoosh, H. Ojaroudi, N. Ojaroudi, "A Compact UWB Slot Antenna with Reconfigurable Band-Notched Function for Multimode Applications”, ACES Journal, vol. 31, No. 1, pp. 14-18, 2016.

[37] M. F. Ismail, M. K. A. Rahim, H. A. Majid, "The Investigation of PIN Diode Switch on Reconfigurable Antenna", IEEE International RF and Microwave Conference (RFM 2011), pp. 234-237, 2011.

[38] H. H. Moghadam, A. Mirkamali, P. S. Hall, "Using Printed Dipole Antenna and PIN Diodes for Wideband Frequency Reconfigurable”, Loughborough Antennas and Propagation Conference, pp. 381-384, 2010.

\section{BIOGRAPHIES OF AUTHORS}

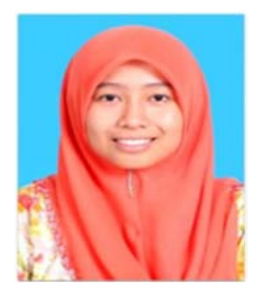

Ika Dewi Saiful Bahri - was born in Malaysia in 1988. She is a PhD Candidate from Universiti Teknikal Malaysia Melaka (UTeM) in the department of Telecommunication Engineering. She received the B. Eng from Universiti Teknologi Malaysia in 2012 (Electrical-Microelectronic) and M. Eng from Kumoh National Institute of Technology, South Korea in 2014 (IT Convergence Engineering). From 2014 to 2016, she was a lecturer at the Faculty of Technical Engineering, UTeM. Currently, she is doing research on reconfigurable filtering antenna for ultra-wideband applications and her interest includes microwave antennas.

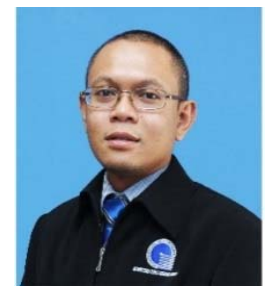

Zahriladha Zakaria, PhD, MIEEE, BEM, Grad IEM - was born in Malaysia in 1975. He received the B. Eng. and M. Eng. in Electrical and Electronic Engineering from the Universiti Teknologi Malaysia in 1998 and 2004 respectively. He obtained his Doctorate from The University of Leeds in 2010 in the area of Microwave Engineering. From 1998 to 2002, he was with STMicroelectronics, based in Malaysia where he worked as Product Engineer. He is currently an Associate Professor at the Faculty of Electronic and Computer Engineering, University Teknikal Malaysia Melaka, where he teaches electronic system, communication principles, microwave engineering, advanced TCP/IP and signal processing. His research interests include variety of microwave devices development such as planar and non-planar microwave filters, amplifiers and antennas. He also investigates data communication and radiowave propagation in wireless communication systems.

Indonesian J Elec Eng \& Comp Sci, Vol. 14, No. 1, April 2019 : 267 - 275 


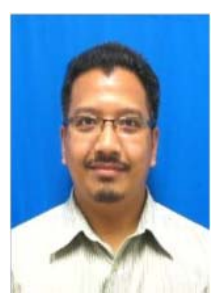

Noor Azwan Shairi, PhD, MIEEE - was born in Malaysia in 1978. He received the Bachelor in Engineering (Electrical-Telecommunication) and the Master in Electrical Engineering (By Research) from Universiti Teknologi Malaysia (UTM), in 2002 and 2005, respectively. In 2015, he obtained his Doctorate from Universiti Teknikal Malaysia Melaka (UTeM) in the field of Electronic Engineering ( $R F$ and Microwave). Currently, he is a Lecturer at the Faculty of Electronics and Computer Engineering (FKEKK), Universiti Teknikal Malaysia Melaka (UTeM), Malaysia. His research areas are mainly focused on RF and Microwave Engineering.

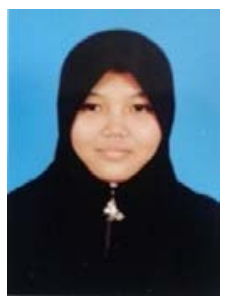

Nurhasniza Edward - was born in Malaysia in 1991. She is a PhD Candidate from Universiti Teknikal Malaysia Melaka (UTeM) in the department of Telecommunication Engineering. Currently, she is doing research on tunable/reconfigurable power divider for wideband applications. Her interest includes RF/Microwave and antennas. 